\title{
KONSEP WALKABILITY DI TROTOAR JALAN DEWI SARTIKA DEPOK PADA AKTIVITAS DI PAGI DAN MALAM HARI
}

\author{
Ksatrya Dwithama ${ }^{1}$, Etty Retnowati Kridarso ${ }^{2}$ \\ 1 Program Magister Arsitektur, Universitas Trisakti, Jakarta \\ 2Jurusan Arsitektur, Universitas Trisakti, Jakarta, 11440 \\ ksatryadwithama@gmail.com,etty.k@.trisakti.ac.id
}

Diterima: 30 Desember 2019

Direvisi: 25 Februari 2020

Disetujui: 25 Maret 2020

\begin{abstract}
ABSTRAK
Trotoar merupakan elemen yang penting dalam perancangan kota, yang diwuiudkan sebagai elemen kenyamanan dan elemen pendukung bagi para penjual eceran serta kehidupan ruang-ruang kota(1). Jl. Dewi Sartika Depok merupakan jalur penghubung antara dua arteri kota Jl. Margonda Raya dan Jl. Sawangan Raya. Selama pertumbuhannya telah terjadi perbedaan fungsi trotoar sisi kiri Jalan Dewi Sartika pada pagi hari dan malam hari jalan dengan digunakannya trotoar sebagai sarana berdagang(2). Penelitian ini bertujuan untuk mengetahui konsep walkability pada trotoar sisi kiri pada pagi dan malam hari, dalam upaya menyediakan fasilitas yang ramah bagi pejalan kaki yang terdapat di kawasan perdagangan. Metode yang dipilih adalah pendekatan kualitatif melalui deskriptif analisis dengan pendekatan observasi terhadap kondisi aktual lapangan. Penelitian ini menghasilkan temuan berupa perbedaan aktivitas pada segmen yang menjual kebutuhan pangan. Konsep walkability tidak sepenuhnya terpenuhi karena trotoar sisi kiri tidak dapat diakses oleh pejalan kaki di beberapa tempat.
\end{abstract}

Kata kunci: Aktivitas, Trotoar, Walkability.

\begin{abstract}
The sidewalk is an important element in urban design, which is manifested as an element of comfort and a supporting element for retailers and the life of urban spaces (1). Jl. Dewi Sartika Depok is a connecting line between two city arteries, Jl. Margonda Raya and Jl. Sawangan Raya. During its growth there has been a difference in the function of the sidewalk on the left side of Jalan Dewi Sartika in the morning and at night on the road with the use of the sidewalk as a means of trading (2). This study aims to determine the concept of walkability on the left hand side sidewalk in the morning and evening, in an effort to provide pedestrian-friendly facilities in the trade area. The method chosen was a qualitative approach through descriptive analysis with an observational approach to the actual conditions of the field. This research produces findings in the form of different activities in segments that sell food needs. The concept of walkability is not fully fulfilled because the left hand side sidewalk is not accessible to pedestrians in several places.
\end{abstract}

Keywords: Activity, Sidewalk, Walkability.

\section{PENDAHULUAN}

Kota Depok adalah Kota yang berada di Selatan Jakarta dengan sebagian besar penduduknya memiliki pekerjaan di Jakarta. Jumlah penduduk Kota Depok pada tahun 
2019 mencapai 2,2 Juta Jiwa ${ }^{(3)}$. Koridor Jl. Dewi Sartika Depok merupakan jalan yang menghubungkan dua arteri antara jalan Raya Sawangan, dengan jalan Margonda Raya. Selama pertumbuhannya telah terjadi perubahan fungsi trotoar pada pagi hari dan malam hari jalan Dewi Sartika dengan digunakannya trotoar sebagai sarana berdagang ${ }^{(1)}$.

Trotoar atau jalur pejalan kaki merupakan elemen yang penting dalam perancangan kota, yang diwuiudkan sebagai elemen kenyamanan dan elemen pendukung bagi para penjual eceran serta kehidupan ruang-ruang kota. Sistem jalur pedestrian dapat mengurangi ketergantungan terhadap kendaraan dalam suatu kota ${ }^{(2)}$. Menciptakan lingkungan yang mendorong orang untuk memilih perjalanan aktif semakin diakui sebagai cara untuk menumbuhkan masyarakat yang lebih berkelanjutan, lebih sehat dan lebih aman ${ }^{(4)}$.

Bagaimanakah kondisi trotoar sisi kiri n pada jalan Dewi Sartika pada pagi dan malam hari terhadap konsep walkability? Apakah terdapat perbedaan aktivitas pada pagi dan malam hari?

Penelitian ini bertujuan Mengetahui kondisi fasilitas bagi masyarakat untuk berjalan kaki terhadap konsep trotoar ramah pejalan kaki pada kawasan perdagangan, diharapkan dapat memberikan kontribusi pada perkembangan ruang publik sebagai wadah aktivitas masyarakat, dan Mengetahui perbedaan aktivitas pada pagi dan malam hari, diharapkan dapat memberikan gambaran yang signifikan dalam upaya menyediakan fasilitas yang ramah bagi pejalan kaki yang terdapat di kawasan perdagangan

Penelitian dilakukan di koridor jalan Dewi Sartika dengan panjang total 610m. penggal koridor yang dipilih adalah sisi kiri dari arah datangnya kendaraan, karena terdapat aktivitas perdagangan di atas trotoar jalan, dengan penggal jalan yang diambil diwakili dengan garis berwarna kuning dengan panjang $300 \mathrm{~m}$.

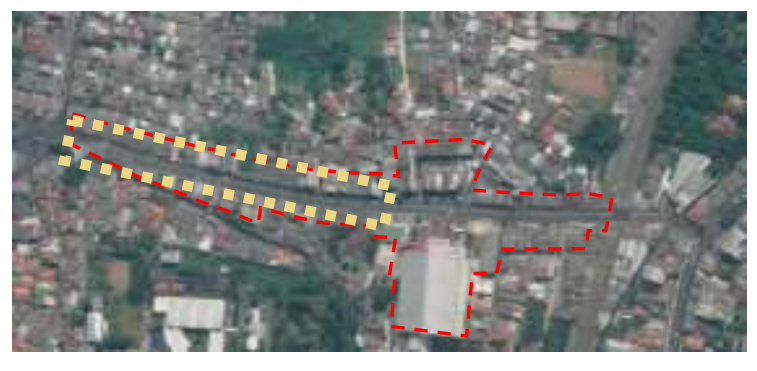

Gambar 1 : Gambar Lokasi Studi (Sumber: Google.com)

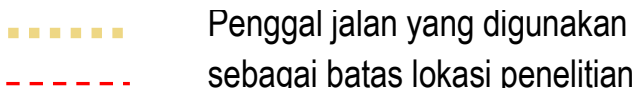


Objek utama yang diteliti adalah aktivitas yang terjadi di atas jalur pejalan kaki pada koridor J1.. Dewi Sartika.

Pengambilan data dilakukan pada 2 waktu yang berbeda ketika terdapat perbedaan aktivitas pada trotoar, yaitu pada pagi dan malam hari.

Manfaat dari penelitian ini mewadahi aktivitas masyarakat yang menggunakan trotar jalan Dewi Sartika, memberikan masukan secara teoritis berkaitan dengan perubahan fungsi trotoar yang dipengaruhi oleh keberadaan fasilitas perdagangan, dan dapat Menjadi refrensi dalam strategi pengembangan Jl. Dewi Sartika.

\section{TINJAUAN PUSTAKA}

\section{Aktivitas}

Perilaku pejalan kaki, seperti aktivitas apa pun, adalah fungsi dari dua set faktor utama, budaya dan fisik. Setiap kegiatan terutama didasarkan pada budaya karena merupakan hasil dari aturan dan kebiasaan yang tidak tertulis. Beberapa budaya cenderung menggunakan ruang perkotaan untuk banyak kegiatan lebih banyak daripada yang lain ${ }^{(6)}$.

Perilaku konsumen adalah tindakan yang langsung terlibat dalam mendapatkan, mengkonsumsi, menghabiskan produk dan jasa, termasuk proses keputusan yang mendahului dan menyusuli tindakan itu ${ }^{(7)}$.

\section{Trotoar}

Menurut kementerian pekerjaan umum, trotar adalah ruas pejalan kaki, area yang diperuntukkan bagi pejalan kaki dan fasilitas yang menunjangnya seperti, jalur bagian depan gedung, jalur pejalan kaki, dan perabot jalan. Hamid Shirvani pada Urban Design Process ${ }^{(1)}$ Elemen sirkulasi perancangan kota merupakan salah satu peralatan yang bermanfaat dalam menyusun lingkungan kota, karena dapat membentuk mengarahkan dan mengontrol pola aktivitas dan pengembangan suatu kota.. 3 prinsip dari sirkulasi adalah :

i. Jalan harus "elemen ruang terbuka visual yang positif"

ii. Berikan orientasi kepada pengemudi dan untuk membuat lingkungan terbaca

iii. Sektor publik dan swasta harus bergabung dalam kemitraan untuk mencapai tujuan ini.

Jalur pedestrian atau jalan bagi para pejalan kaki merupakan elemen yang penting dalam perancangan kota, yang diwuiudkan sebagai elemen kenyamanan dan elemen pendukung bagi para penjual eceran serta kehidupan ruang-ruang kota. Sistem jalur pedestrian dapat membentuk aktivitas pedagang eceran dan memperbaiki kualitas udara.

Kriteria jalur Pedestrian adalah :

i. Interaksi antara elemen desain perkotaan dasar 
ii. Sangat terkait dengan lingkungan dan aktivitas bangunan yang ada

iii. Efektif dengan perubahan fisik masa depan di kota

Kebutuhan Ruang Pejalan Kaki berdasarkan dimensi tubuh yang lengkap berpakaian adalah $45 \mathrm{~cm}$ untuk tebal tubuh sebagai sisi pendeknya dan $60 \mathrm{~cm}$ untuk lebar bahu sebagai sisi panjangnya. Berdasarkan perhitungan dimensi tubuh manusia, kebutuhan ruang minimum pejalan $\mathrm{kaki}^{\left({ }^{(9)}\right.}$ :

i. tanpa membawa barang dan keadaan diam yaitu $0,27 \mathrm{~m} 2$

ii. tanpa membawa barang dan keadaan bergerak yaitu $1,08 \mathrm{~m} 2$

iii. membawa barang dan keadaan bergerak yaitu antara 1,35 m2 -1,62 m2
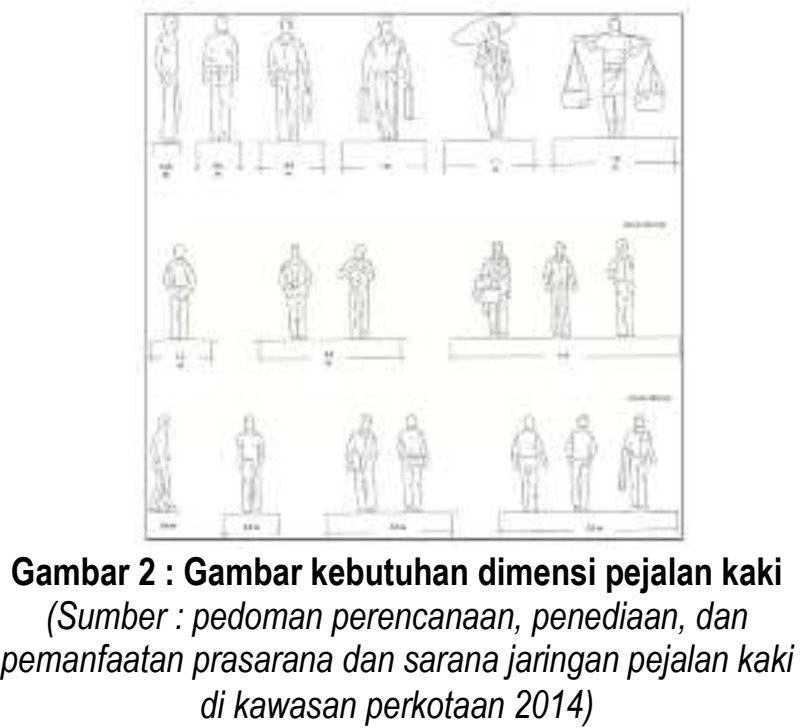

\section{Walkability}

Walkability menurut Land Transport New Zealand.. pedestrian planning and design guide, adalah suatu kondisi yang menggambarkan sejauh mana suatu lingkungan dapat bersifat ramah terhadap para pejalan $\mathrm{kaki}^{(8)}$. Berikut adalah poin-poin yang menjadi prioritas utama dalam menciptakan suatu lingkungan yang walkable. ${ }^{(9)}$

i. Pengumpulkan informasi umum tentang kawasan, seperti : Tanggal, lokasi dan waktu, penggunaan lahan, pengguna utama, kondisi cuaca, kesan keseluruhan walkability pada kawasan

ii. Jalur pedestrian yang berdekatan dengan pagar pembatas

iii. kondisi path tidak berpotensi menyebabkan bahaya. Jalur path harus dapat dirancang dengan perkerasan yang halus tidak bergelombang serta anti selip 
iv. Tidak terdapat penghalangberupa objek yang bersifat sementara seperti, kursi sebuah restoran yang bersifat portable, tiang listrik, tempat pemberhentian bus, ataupun pepohonan.

v. perletakan lokasi penyeberangan perlu disediakan untuk memudahkan menyebrang dengan aman dan mudah

vi. street furniture berupa bangku taman tempat sampah ataupun toilet umum ataupun naungan pembentuk bayangan

vii. suatu lingkungan perlu memiliki tingkat penerangan yang baik, khususnya pada malam hari

viii. membatasi kecepatan kendaraan bermotor pada kawasan

ix. adanya lansekap atau karya seni yang menarik

\section{METODOLOGI}

Metode penelitian yang digunakan adalah metode kuantitatif melalui deskriptif analisis, dengan cara survey lapangan, studi dokumentasi/pustaka, kuesiner dan wawancara (Hidayat, 2011). Pengumpulan data dilakukan melalui pengamatan langsung, wawancara dengan menggunakan kuesioner, dan studi pustaka. Data fisik terdiri atas dimensi jalur pedestrian, material jalur pedestrian, kebersihan, perlengkapan jalan, kemudahan pencapaian, dimensi pakir kendaraan dan vegetasi jalur pedestrian. Data persepsi diperoleh dengan cara membagikan kuesioner mengenai kondisi eksisting kenyamanan sirkulasi dalam jalur pedestrian. Responden terdiri dari 40 orang responden yang berpotensi menggunakan jalur pedestrian.

Pengolahan data mengenai persepsi menggunakan skala Semantic Differential Method dengan skala 4 nilai. Nilai 1 menunjukan sangat kurang, nilai 2 menunjukan kurang, nilai 3 menunjukan baik, dan nilai 4 menunjukan sangat baik. Hasil olah data tersebut kemudian dicari persentasenya untuk selanjutnya dideskripsikan berdasarkan rentang kriteria kenyamanan.

\section{METODE PENELITIAN}

Metode yang dipilih adalah pendekatan kualitatif melalui deskriptif analisis dengan pendekatan observasi terhadap kondisi aktual lapangan saat ini $^{(12)}$ dan melakukan pengambilan data lapangan terhadap aktivitas yang terjadi di trotoar sisi kiri pada pagi dan malam hari berdasarkan kajian teori dan kriteria dari konsep ramah pejalan kaki.

Pengumpulan data penelitian yang dilakukan dengan mengumpulkan data primer berupa observasi kondisi aktual lapangan pada pagi hari pada pukul 09.00 WIB dan malam hari mulai pukul $20.00 \mathrm{WIB}$, pengukuran menggunakan alat ukur, rekaman visual untuk dokumentasi keadaan lokasi, dan wawancara. 
Untuk mengumpulkan data dari sampel penelitian, dilakukan dengan metode tertentu sesuai tujuannya, antara lain wawancara, pengamatan (observasi), dan dokumenter (foto/sketsa).

Penelitian dilakukan dengan mengamati aktivitas yang terjadi di trotoar selama waktu penelitian yaitu pagi dan malam hari. Hal ini dilakukan karena melalui observasi awal, ditemukan bahwa pada obyek penelitian pemanfaatan ruang terus berubah dan tidak pernah sepi dari aktivitas pedagang.

Pada penelitian ini yang diamati yaitu dimensi koridor, lebar jalan, dimensi trotoar, jenis dagangan, dan areal yang digunakan oleh para pedagang untuk menggelar dagangannya. Selain itu juga diadakan pendataan terhadap aktivitas lain yang menempati badan jalan atau jalur pedestrian, antara lain : tempat parkir, dan PKL. Pendataan tersebut dilakukan dengan pengukuran untuk memperoleh dimensi yang diperlukan.

Pengamatan terhadap jalur jalan, jalur pedestrian serta bangunan yang berada disepanjang penggal jalan lokasi penelitian. Data yang diperoleh tersebut merupakan unit informasi, yaitu berupa dimensi jalan, jalur pedestrian serta pendataan jenis bangunan dan pengukuran masing-masing bangunan yang dijadikan data primer.

\section{HASIL \& PEMBAHASAN}

Dari hasil pengamaatan awal di lapangan. Terdapat dua jenis pedagang yang berjualan di atas jalur pedestrian. Yang pertama pedagang yang berjualan bahan pokok seperti daging, dan sayur, yang kedua berjualan baju dan sepatu. Pedagang yang menjual bahan makanan aktif dari pagi hingga sore hari. Sementara pedagang yang berjualan pakaian, berjualan dari pagi hingga malam hari.

Tingginya aktivitas perdagangan dan jumlah kendaraan yang melewati Jl. Dewi Sartika, jalan ini memiliki potensi tinggi sebagai jalan yang strategis bagi para pedagang. Diperlukannya sebuah penelitian untuk membandingan tingkat aktivitas kegiatan pada trotar jalan ini pada dua waktu yang berbeda yaitu pagi, dan malam hari.

Jalan Dewi Sartika merupakan jalan penghubung dua jalan arteri primer dan menjadi akses bagi masyakarat Depok yang berada di daerah Sawangan (selatan depok) untuk mencapai Jl. Margonda Raya yang merupakan pusat kegiatan di Kota Depok.

Koridor jalan Dewi Sartika memiliki panjang total $610 \mathrm{~m}$. penggal koridor yang dipilih karena terdapat aktivitas perdagangan di atas trotoar jalan dengan panjang $300 \mathrm{~m}$. Pada Jalan 
Dewi Sartika, terdapat trotoar pada kedua sisi jalannya, namun pejalan kaki tidak dapat menggunakannya karena terdapat aktivitas perdagangan pada trotoar



\section{Gambar 3 Gambar area lokasi studi}

(Sumber: Data Pribadi)

Tingkat kepadatan kendaraan di Jalan ini sangat tinggi. Sepanjang koridor jalan, terdapat pedagang kaki lima yang berjualan di atas jalur pedestrian pada siang dan malam hari.Dari hasil pengamaatan, terdapat dua jenis pedagang yang berjualan di atas jalur pedestrian. Yang pertama pedagang yang berjualan bahan pokok seperti daging, dan sayur, yang kedua berjualan baju dan sepatu. Pedagang yang menjual bahan makanan aktif dari pagi hingga sore hari. Sementara pedagang yang berjualan pakaian, berjualan dari pagi hingga malam hari.

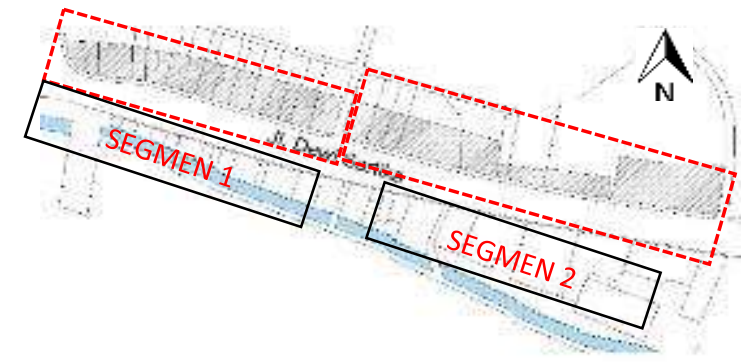

\section{Gambar 4. Pembagian Segmen pembahasan} (sumber: Data Pribadi)

Dalam membuat laporan aktivitas pada jl Dewi sartika pada pagi dan malam hari. Penggal jalan yang telah ditentukan akan diambil sisi kiri dari arah datangnya kendaraan. Batas lokasi pembahsan akan dibagi menjadi 2 segmen untuk memudahkan pembahasan, pembagian segmen ditetapkan berdasarkan batas fisik blok bangunan sisi kiri jalan, dengan jalan lingkungan sebagai pembatasnya. Pengambilan penggal jalan ini berdasarkan tingginya aktivitas perdagangan pada sisi kiri jalan. 


\section{Segmen 1}

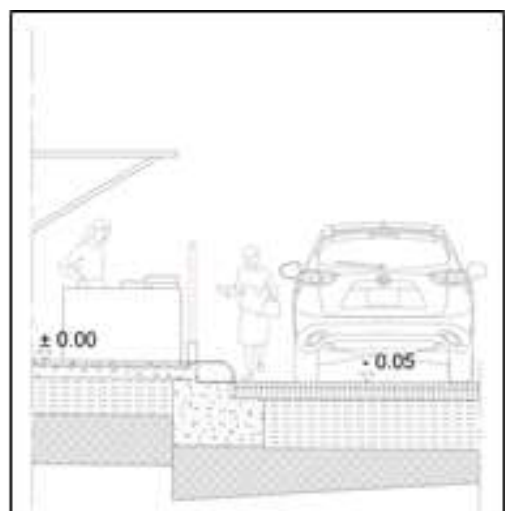

Gambar 5. Sketsa Kondisi trotoar saat ini

(Summber: Datta Pribadi)

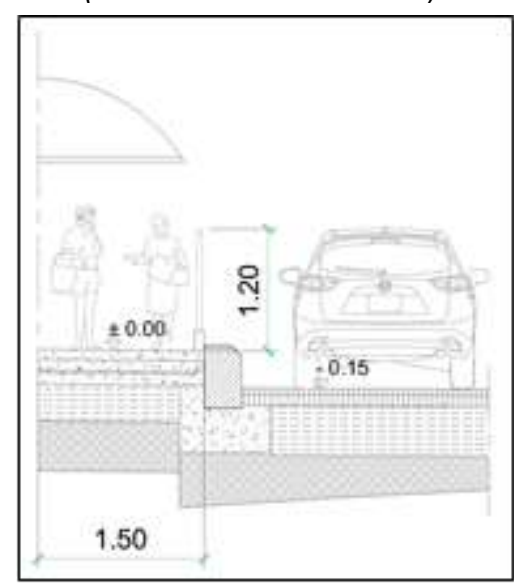

Gambar 6. Sketsa Kondisi ideal trotoar pada jalan Dewi Sartika (Sumber: Data Pribadi)



Gambar 7. Foto Keadaan trotoar Segmen 1 (sumber: Data Pribadi) 
Dari hasil observasi pada segmen 1 diketahui bahwa pada koridor jl. Dewi Sartika terdapat trotoar yang memiliki lebar 1.5 meter. Pada trotoar yang digunakan untuk aktivitas perdagangan di pagi hari. Pada malam hari aktivitas perdagangan jumlahnya sudah jauh berkurang sehingga trotoar dapat diakses pada beberapa tempat. Di beberapa tempat masih terdapat perlengkapan pedagang yang berjualan pada pagi hari.

- Pada segmmen 1, konsep ramah pejalan kaki (walkability) terdapat di beberapa titik berupa terdapatnya pagar pembatas antara jalan dan trotoar, tersedianya penutup atap bagi pejalan kaki yang disediakan oleh toko - toko. Namun pada siang hari pejalan kaki cenderung tidak dapat mengakses trotoar dikarenakan aktivitas perdagangan yang ada di segmen 1. Terdapat pula titik yang memiliki perbedaan ketinggian pada trotoar sehingga tidak dapat melayani kaum diffabel. Lebar trotoar $1.5 \mathrm{~m}$

- Terdapat pagar pembatas antara jalan dan trotoar di sepanjang segmen 1.

- Kondisi trotoar terdapat perbedaan ketinggian di atas trotoar, penutup saluran air yang berada di atas trotoar tidak terpasang, terdapat material - material trotoar yang tidak terpasang.

- Terdapat objek yang menghalangi aktivitas pejalan kaki di atas trotoar berupa meja meja lapak pedagang pada pagi dan malam hari. Pada pagi hari terdapat meja dan pedagang yang aktif berjualan di atas trotoar mengakibatkan pejalan kaki harus berjalan di atas jalan utama.

- Sepanjang segmen 1 tidak terdapat fasilitas untuk menyebrang jalan

- Tidak terdapatnya tempat sampah di sepanjang trotoar, namun terdapat atap penutup trotoar yang disediakan oleh pedagang untuk menutup dagangan mereka pada pagi hari.

- Penerangan tersedia berupa lampu - lampu dari toko

\section{Segmen 2}

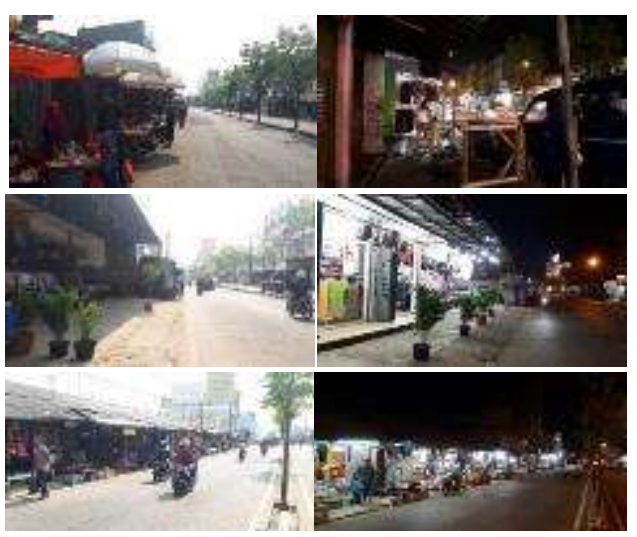

Gambar 8. Foto perbandingan Segmen 2

(Sumber: Data Pribadi) 
Pada segmen 2 trotoar, lebih didominasi oleh pedagang yang menjual pakaian dan perlengkapan rumah tangga. Aktivitas perdagangan juga terdapat di atas trotoar. Pejalanan kaki menggunakan bahu jalan Dewi Sartika untuk berjalan kaki.

Aktivitas di trotoar segmen 2 mengalami penurunan pada bagian barat yaitu pada tempat terdapatnya toko toko yang menjual bahan pangan. Pada bagian timur aktivitas perdagangan tetap terjadi dikarenakan toko pada bagian timur menjual baju, sehingga trotar masih tidak bias diakses oleh pejalan kaki.

Pada segmen 2 ini juga terdapat toko dengan ukuran besar, pada bagian depan toko ini terdapat lahan parkir dan tempat pejalan kaki, Namun pagar besi pembatas jalan dengan trotoar yang terdapat di segmen 1 tidak ada pada bagian ini.

Konsep Walkability pada segmen 2 :

- Dimensi trotoar $1.5 \mathrm{~m}$ dan terdapat lebar trotoar yang mencapai $2 \mathrm{~m}$

- Pada segmen 2 terdapat banyak titik yang sudah tidak memiliki pagar pembatas antara trotoar dan jalan utama, dikarenakan sudah menjadi lahan parkir kendaraan maupun bangunan permanen dan semi permanen dari toko - toko di atas trotoar.

- Kondisi fisik trotoar, di beberapa titik fisik trotoar sudah tidak terlihat lagi dikarenakan telah diubah menjadi lahan parkir maupun toko - toko.

- Terdapat objek yang menghalangi alur pejalan kaki berupa bangunan toko yang berbentuk pemanen maupun semi permanen.

- Sepanjang segmen 2 tidak terdapat fasilitas bagi pejalan kaki untuk menyebrang jalan.

- Tidak terdapat tempat sampah di sepanjang trotoar, namun terdapat atap penutup trotoar yang disediakan oleh pedagang untuk menutup dagangan mereka pada pagi hari.

- Penerangan tersedia berupa lampu - lampu dari toko.

\section{SIMPULAN}

Aktivitas di trotoar jl. Dewi Sartika memiliki perbedaan pada pagi dan malam hari. Pada pagi hari aktivitas perdagangan lebih tinggi pada segmen 1 yang menjual barang kebutuhan harian. Hal ini diduga karena pada pagi hari banyak toko/lapak yang menjual kebutuhan pangan seperti sayur dan daging yang dijual sebagai pemenuh kebutuhan pokok masyarakat yang tinggal di area sekitar jl. Dewi Sartika.

Pada pagi hari trotoar pada segmen 1 yang didominasi oleh pedagang dengan kebutuhan pokok terdapat trotoar dengan lebar 1.5 meter dengan pembatas pagar besi memiliki 
aktivitas tinggi sehingga pejalan kaki menggunakan bahu jalan untuk berjalan. Trotoar ini tidak dapat diakses pada pagi hari, dan pada malam hari ketika aktivitas perdagangan sudah berkurang, trotoar dapat diakses dengan keadaan masih terdapat perlengkapan pedagang yang berjualan di pagi hari.

Segmen 2 lokasi penelitian didominasi oleh toko pakaian yang beroperasi dari pagi hingga malam hari. Sehingga aktivitas perdagangan tidak terdapat perbedaan yang signifikan. Para pedagang menggunakan trotoar sebagai tempat berjualan. Terdapat toko dengan ukuran besar yang menyediakan lahan parkir, namun pada bagian toko ini trotoar yang pada awal memiliki lebar 1.5 meter dengan pagar besi sebagai pembatas tidak ada, digantikan dengan lahan parkir toko tersebut.

Perbedaan aktivitas terdapat pada bagian trotoar yang banyak menjual kebutuhan pangan, pada pagi hari tingkat aktivitas sangat tinggi, namu pada malam hari tidak terdapat aktivitas sehingga trotoar dapat diakses pejalan kaki dengan keadaan barang para pedagang tetap berada di trotoar.

Perbedaan aktivitas trotoar antara pagi dan malam hari terjadi karena pada pagi hari aktivitas didominasi oleh pedagang yang menjual bahan makanan, makanan, dan barang kebutuhan rumah tangga. Toko - toko yang menjual barang tersebut pada malam hari tutup dikarenakan pembeli yang membeli jenis barang dagangan tersebut lebih tinggi intensitasnya pada pagi hari karena barang dagangan tersebut bersifat pemenuh kebutuhan harian, sehingga trotoar dapat diakses oleh pejalan kaki. Sedangkan toko yang menjual Konsep ramah pejalan kaki pada trotoar di penggal jalan Dewi Sartika:

- Dimensi trotoar $1.5 \mathrm{~m}$ dan terdapat lebar trotoar yang mencapai $2 \mathrm{~m}$ yang sudah sesuai dengan dimensi untuk pejalan kaki.

- Terdapat bagian trotoar yang sudah tidak memiliki pagar pembatas antara trotoar dan jalan utama, dikarenakan sudah menjadi lahan parkir kendaraan maupun bangunan permanen dan semi permanen dari toko - toko di atas trotoar.

- Kondisi fisik trotoar terdapat perbedaan ketinggian pada trotoar, dan di beberapa titik fisik trotoar sudah tidak terlihat lagi dikarenakan telah diubah menjadi lahan parkir maupun toko - toko.

- Terdapat objek - objek yang menghalangi alur pejalan kaki berupa meja - meja pedagang, dan bangunan toko yang berbentuk pemanen maupun semi permanen.

- Sepanjang penggal jalan tidak terdapat fasilitas bagi pejalan kaki untuk menyebrang jalan. 
- Tidak terdapat tempat sampah di sepanjang trotoar, namun terdapat atap penutup trotoar yang disediakan oleh pedagang untuk menutup dagangan mereka pada pagi hari.

- Penerangan tersedia berupa lampu - lampu dari toko.

\section{DAFTAR RUJUKAN}

Dinas Kependudukan dan Catatan Sipil Kota Depok, (2019).

Engel, Blackwell, Miniard. (2012). Perilaku Konsumen. Tangerang: Binarupa Aksara.

Government of Western Australia Department of Transport, "Walkabilty audit tool," (2011)

Government of Western Australia Department of Transport, Walkabilty audit tool. (2011)

Kementerian Pekerjaan Umum "pedoman perencanaan, penediaan, dan pemanfaatan prasarana dan sarana jaringan pejalan kaki di kawasan perkotaan”. (2014)

Nugroho, Y.A. (2018). Keamanan dan Kenyaman Trotoar di Taman Tingkir, Kota Salatiga. Mintakat Jurnal Arsitektur, 19 (1).

NZ Transport Agencies. (2009). "Pedestrian planning and design guide",

Rapoport, A. (1969) Pedestrian Use: Eaglewood Cliffs

Mashudi R. (2014 ). Strategi Pentaan Pedagang Kaki Lima di Jalan Dewi Sartika. Journal ipb.

Shirvani, H. (1984). “The Urban Design Process". Van Nostrand Reinhold.

Sugiyono. (2012). Metode Penelitian Pendidikan Pendekatan kwantitatif, kwalitatif, dan R\&D: Bandung alfabeta. 